Subscriber access provided by Caltech Library

Anthropogenic Impacts on the Atmosphere

\title{
Stability of Monoterpene-Derived \#-Hydroxyalkyl- Hydroperoxides in Aqueous Organic Media - Relevance to the Fate of Hydroperoxides in Aerosol Particle Phases
} Junting Qiu, Zhancong Liang, Kenichi Tonokura, Agustín J. Colussi, and Shinichi Enami

Environ. Sci. Technol., Just Accepted Manuscript • DOI: 10.1021/acs.est.9b07497 • Publication Date (Web): 04 Mar 2020

Downloaded from pubs.acs.org on March 5, 2020

\section{Just Accepted}

"Just Accepted" manuscripts have been peer-reviewed and accepted for publication. They are posted online prior to technical editing, formatting for publication and author proofing. The American Chemical Society provides "Just Accepted" as a service to the research community to expedite the dissemination of scientific material as soon as possible after acceptance. "Just Accepted" manuscripts appear in full in PDF format accompanied by an HTML abstract. "Just Accepted" manuscripts have been fully peer reviewed, but should not be considered the official version of record. They are citable by the Digital Object Identifier (DOI®). "Just Accepted" is an optional service offered to authors. Therefore, the "Just Accepted" Web site may not include all articles that will be published in the journal. After a manuscript is technically edited and formatted, it will be removed from the "Just Accepted" Web site and published as an ASAP article. Note that technical editing may introduce minor changes to the manuscript text and/or graphics which could affect content, and all legal disclaimers and ethical guidelines that apply to the journal pertain. ACS cannot be held responsible for errors or consequences arising from the use of information contained in these "Just Accepted" manuscripts. 


\section{Stability of Monoterpene-Derived $\alpha$-Hydroxyalkyl-}

Hydroperoxides in Aqueous Organic Media - Relevance to the Fate of Hydroperoxides in Aerosol Particle Phases Environmental Studies, 16-2 Onogawa, Tsukuba 305-8506, Japan.

\section{Junting Qiua , Zhancong Liang ${ }^{b}$, Kenichi Tonokuraa , Agustín J. Colussi*c, Shinichi Enami*d}

${ }^{a}$ Graduate School of Frontier Sciences, The University of Tokyo, 5-1-5 Kashiwanoha, Kashiwa 277-8563, Japan. 'bshool of Atmospheric Sciences, Sun Yat-sen University, Guangzhou, 510275, China. ${ }^{C}$ Ronald and Maxine Linde Center for Global Environmental Science, California Institute of Technology, Pasadena, California, 91125, U.S.A. ${ }^{d}$ National Institute for

ABSTRACT - The $\alpha$-hydroxyalkyl-hydroperoxides $[\mathrm{R}-(\mathrm{H}) \mathrm{C}(-\mathrm{OH})(-\mathrm{OOH}), \alpha-\mathrm{HH}]$ produced in the ozonolysis of unsaturated organic compounds may contribute to SOA aging. $\alpha-\mathrm{HH}$ inherent instability, however, hampers their detection and a positive assessment of their actual role. Here we report, for the first time, the rates and products of the decomposition of the $\alpha-\mathrm{HHs}$ generated in the ozonolysis of atmospherically important monoterpenes $\alpha$-pinene $(\alpha-P), d$ limonene $(d-\mathrm{L}), \gamma$-terpinene $(\gamma$-Tn) and $\alpha$-terpineol $(\alpha$-Tp) in water:acetonitrile (W:AN) mixtures. We detect $\alpha-\mathrm{HH}$ and multifunctional decomposition products as chloride-adducts by online electrospray ionization mass spectrometry. Experiments involving $\mathrm{D}_{2} \mathrm{O}$ and $\mathrm{H}_{2}{ }^{18} \mathrm{O}$ instead of $\mathrm{H}_{2}{ }^{16} \mathrm{O}$, and an $\mathrm{OH}$-radical scavenger show that $\alpha$-HHs decompose into gem-diols + $\mathrm{H}_{2} \mathrm{O}_{2}$ rather than free radicals. $\alpha-\mathrm{HHs}$ decay mono- or bi-exponentially depending on molecular structure and solvent composition. e-fold times, $\tau_{1 / \mathrm{e}}$, in water-rich solvent mixtures range from $\tau_{1 / \mathrm{e}}=15-45 \mathrm{~min}$ for monoterpene-derived $\alpha$-HHs to $\tau_{1 / \mathrm{e}}>10^{3} \mathrm{~min}$ for the $\alpha-\mathrm{Tp}$ - 

derived $\alpha-H H$. All $\tau_{1 / \text { e }}$ 's dramatically increase in $<20 \%$ (v:v) water. Decay rates of the $\alpha-T p-$ derived $\alpha-\mathrm{HH}$ in pure water increase at lower $\mathrm{pH}(2.3 \leq \mathrm{pH} \leq 3.3)$. The hydroperoxides detected in day-old SOA samples may reflect their increased stability in water-poor media and/or the slow decomposition of $\alpha-\mathrm{HH}$ from functionalized terpenes.

29

30 


\section{INTRODUCTION}

The detection of extremely low-volatility organic compounds (ELVOCs) ${ }^{1-3}$ has gone a long way to explaining how biogenic volatile organic compounds (VOCs) contribute to the formation of secondary organic aerosol (SOA). ${ }^{4}{ }^{5}$ ELVOCs are mostly produced during the ozonolysis of monoterpenes $\left(\mathrm{C}_{10} \mathrm{H}_{16}\right)$, particularly those containing endocyclic double bonds such as $\alpha$-pinene (see Scheme 1), 2, 6 and condense as nanoparticles. High-resolution chemical ionization mass spectrometry reveals that $\alpha$-pinene ELVOCs consist of highly oxidized monomeric $\mathrm{C}_{x=8-10} \mathrm{H}_{\mathrm{y}=12-16} \mathrm{O}_{z=6-12}$ and dimeric $\mathrm{C}_{x=17-20} \mathrm{H}_{\mathrm{y}=26-32} \mathrm{O}_{z=8-18}$ species. ${ }^{1,3}$ The mechanism of ELVOCs formation proceeds via Criegee intermediates (Cls) that isomerize, fragment or undergo reactions with hydroxylic species such acids, alcohols and water. ${ }^{7-10}$ The fragmentation of $\mathrm{Cls}$ produces alkylperoxyl (R'OO.) radicals that undergo fast intramolecular $\mathrm{H}$-transfers into hydroperoxides and second generation $\mathrm{R}^{\prime \prime} \mathrm{OO}$. radicals. ${ }^{11,} 12$ The latter propagate an autoxidation mechanism that produces ELVOCs possessing multiple hydroperoxide functionalities and elevated $\mathrm{O} / \mathrm{C}$ ratios. ${ }^{13-15} \mathrm{Cls}$ also react with water yielding $\alpha$-hydroxyalkyl-hydroperoxides $(\mathrm{R}-(\mathrm{H}) \mathrm{C}(-\mathrm{OOH})(-\mathrm{OH}), \alpha-\mathrm{HHs}) .^{7,14}$ contained in the highly oxygenated molecules (HOMs) produced in the ozonolysis of $\alpha$-pinene (quantified by iodometry) ${ }^{21}$, however, decompose (into unidentified products) in tens of minutes at ambient temperature. ${ }^{22}$

Clearly, a better understanding of the factors that control the stabilities of hydroperoxides, and the identity of their decomposition products in condensed phases will 
help assess their actual role in SOA chemistry and, as potential sources of reactive oxygen species (ROS), the toxicity of ambient particulate matter. ${ }^{23}$ Here, we investigate the products and decomposition rates of four atmospherically relevant monoterpene-derived $\alpha$-HHs in aqueous organic solutions at ambient temperature for the first time. Since $\alpha$-HHs are the least stable hydroperoxides, ${ }^{18}$ their lifetimes should provide a lower bound to the lifetimes of hydroperoxides, and insights into structural and matrix effects on $\alpha-\mathrm{HHs}$ persistence.

Recently, we found that the $\alpha-\mathrm{HH}$ senerated from the ozonolysis of the sesquiterpene $\beta$-caryophyllene in water:acetonitrile (W:AN) mixtures containing $\mathrm{NaCl}$ (an inert cosolute that does not react with $\mathrm{O}_{3}$ during our experiments) could be detected as chloride-adducts by electrospray ionization mass spectrometry (ESI-MS). ${ }^{24,25}$ The same study showed that $\alpha-\mathrm{HHs}$ decay in a couple of hours in $\geq 20 \%$ (v:v) water mixtures, but persist longer than a day in $<10$ vol \% water. ${ }^{25}$ The goal of the present study is to investigate the effects of chemical structure and other functional groups on the stability of $\alpha-\mathrm{HH}$. This information may help evaluate the fate of atmospherically relevant $\alpha-\mathrm{HH}$ in general. Here we report the rates of decomposition of $\alpha$-HHs produced in the ozonolysis of $\alpha$-pinene $(\alpha-P), d$-limonene $(d-L), \gamma$-terpinene $(\gamma-T n)$, and $\alpha$-terpineol ( $\alpha$-Tp) (Scheme 1 ) in W:AN mixtures of variable composition. Our study focuses on $\alpha-P$ as the most abundant biogenic monoterpene, whose global annual emissions (66.1 Tg) vastly exceed those of related $\beta$-pinene $(18.9 \mathrm{Tg})$ and limonene $(11.4 \mathrm{Tg}) .{ }^{26}$ We take advantage of the high solubility of $\alpha$-Tp in pure water to investigate the effects of $\mathrm{pH}$ on $\alpha$ $\mathrm{HH}$ decay rates. The main findings are that in aqueous organic media monoterpene $\alpha-\mathrm{HHs}$ decompose into hydrogen peroxide plus aldehydes rather than free radicals in tens of minutes, with $e$-fold decay times, $\tau_{1 / \mathrm{e}}$, that depend sensitively on water content and the presence of substituents. The fact that $\tau_{1 / \mathrm{e}}$ 's depend non-linearly on water content for all tested terpenes, strongly suggest that similar behaviors should be expected for the $\alpha-\mathrm{HHs}$ produced in aqueous media in the atmosphere. We found that the decomposition of the $\alpha$ - 
$81 \mathrm{Tp}$-derived $\alpha-\mathrm{HH}$ in water is accelerated at lower $\mathrm{pH}$ in the range of acidities prevalent in cloud water and aqueous aerosols. The main finding, however, is that hydroperoxides and $\alpha-$ hydroxyalkyl-hydroperoxides may not produce reactive free radicals by thermal ${ }^{16,27-29}$ or photochemical O-O homolysis under atmospheric conditions. ${ }^{30}$ Among organic peroxides, only diacyl peroxides could appreciably decompose into free radicals at ambient temperatures. ${ }^{18,31}$

87

88

89

90

91

Scheme 1. Chemical Structures of the Monoterpenes Used in the Present Study

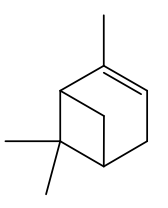

$\alpha$-pinene ( $\alpha$-P)

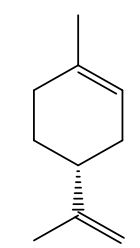

$d$-limonene $(d-\mathrm{L})$

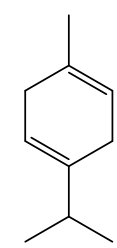

$\gamma$-terpinene $(\gamma$-Tn)

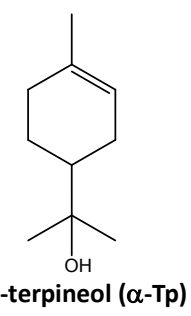

\section{EXPERIMENTAL SECTION}

Figure S1 shows a schematic diagram of our experimental procedure for preparing $\alpha-\mathrm{HHs}$ in solution. ${ }^{24}$ Monoterpenes $\left(\mathrm{C}_{10} \mathrm{H}_{16}, \mathrm{MW}\right.$ 136.13) or $\alpha-\mathrm{Tp}\left(\mathrm{C}_{10} \mathrm{H}_{16} \mathrm{OH}, \mathrm{MW} 154.14\right)$ and $\mathrm{NaCl}$ were dissolved in $10 \mathrm{~mL}$ of $\mathrm{W}$ :AN mixtures $(10,20,30,40,50,60$ vol \% W for $\alpha-P, 20,50$ vol \% W for $d-\mathrm{L}, 20,50$ vol \% W for $\gamma$-Tn, and 50, 100 vol \% W for $\alpha-T p)$ in a glass vial ( $25 \mathrm{~mL}$ ). Note that the low solubilities of $\alpha-P(0.018 \mathrm{mM})^{32}$ and other monoterpenes (except for $\alpha-T p$ ) preclude these studies in neat water. We use W:AN mixtures as surrogates of environmental aqueous $\mathrm{SOA}$ due to $\mathrm{AN}$ polarity and low reactivity toward $\mathrm{O}_{3}$ and free radicals (SOA produced from the ozonolysis of $\alpha$-pinene mainly consists of mixtures of polar hydrophilic species, such as di-carboxylic acids and esters, as well as some high-molecular weight $\mathrm{HOMs}$ ). ${ }^{33} \mathrm{O}_{3}$ solutions were prepared separately by sparging $10 \mathrm{~mL}$ of the same W:AN mixtures in a $25 \mathrm{~mL}$ vial with $\mathrm{O}_{3}(\mathrm{~g})$ from a commercial ozonizer (KSQ-050, Kotohira, Japan) fed with ultrahigh purity $\mathrm{O}_{2}(\mathrm{~g})$ 

at $1 \mathrm{~L} / \mathrm{min}$ flow rate (set by a digital mass flow controller) for $5 \sim 20$ seconds. $\mathrm{O}_{3}$ concentrations in the sparged solutions, $\left[\mathrm{O}_{3}(\mathrm{sol})\right]$, were determined by UV-Vis spectroscopy (Agilent 8453 ) based on the reported $\mathrm{O}_{3}$ molar extinction coefficient in the near-UV: $\varepsilon_{258 \mathrm{~nm}}=3840 \mathrm{M}^{-1} \mathrm{~cm}^{-1}$ in water, ${ }^{34}$ which is expected to be largely unaffected by the presence of $\mathrm{AN} .{ }^{35}$ Reactions were initiated by mixing terpene and ozone solutions ( $2.5 \mathrm{~mL}$ each) in a glass syringe $(5 \mathrm{~mL})$ covered with aluminum foil to avoid the photo-degradation. To minimize unwanted secondary reactions, terpene concentrations were always in excess: [terpene $]_{0} /\left[\mathrm{O}_{3}(\mathrm{sol})\right]_{0}>15$. These mixtures were immediately injected (at $100 \mu \mathrm{L} \mathrm{min}{ }^{-1}$ by a syringe-pump, Harvard apparatus) into an ESI mass spectrometer (Agilent 6130 Quadrupole LC/MS Electrospray System at NIES, at Tsukuba). The $\mathrm{pH}$ of solutions was measured with a calibrated $\mathrm{pH}$ meter (LAQUA F-74, Horiba) before experiments. The evolution of $\alpha-\mathrm{HH}$ and other species were followed by ESIMS as a function of time, recorded with a digital stopwatch.

The prominent feature of our experiments is that the presence of sub-millimolar $\mathrm{NaCl}$ allows us to detect by online ESI-MS, and unambiguously establish the molecular mass of $\alpha$ $\mathrm{HHs}$ and other multifunctional species (such as those containing $-\mathrm{OOH},-\mathrm{OH}$ and $-\mathrm{C}=\mathrm{O}$ groups) as chloride adducts without further manipulation. ${ }^{7,36-42}$ We verified that the monofunctional tert-butyl hydroperoxide (TBHP), cumene hydroperoxide (CHP) as well as difunctional 1,6hexanediol do not produce detectable $\mathrm{Cl}^{-}$-adducts in the presence of $\mathrm{NaCl}$. The implication is that species should contain at least three functional groups to be detected as a $\mathrm{Cl}^{-}$-adduct by ESI-MS. Chloride-adducts characteristically appear as $3: 1$ doublets at $m / z=M+35(+37)$ in the mass spectra. ${ }^{7-10,43,44}$ We verified that $\mathrm{Cl}^{-}$is inert toward $\mathrm{O}_{3}\left(k \approx 1 \times 10^{-2} \mathrm{M}^{-1} \mathrm{~s}^{-1}\right)$ in the time scale of our experiments. ${ }^{36}$ 
fragmentor voltage: $60 \mathrm{~V}$. All solutions were prepared in ultrapure water (Resistivity $\geq 18.2$ $\mathrm{M} \Omega \mathrm{cm}$ at $298 \mathrm{~K}$ ) from a Millipore Milli-Q water purification system and used within a day.

131 Chemicals: (-)- $\alpha$-pinene ( $\geq 95 \%$, Wako or $\geq 99 \%$ Sigma-Aldrich), $d$-limonene (> 99.0\%, Tokyo

132 Chemical Industry), $\gamma$-terpinene (> 95.0\%, Tokyo Chemical Industry), $\alpha$-terpineol (> 97.0\%,

133 Tokyo Chemical Industry), tert-butyl hydroperoxide (70 wt. \%, Sigma-Aldrich,), cumene 134 hydroperoxide (> $80 \%$, Tokyo Chemical Industry), 1,6-hexanediol (> $97 \%$, Tokyo Chemical 135 Industry), acetonitrile ( $\geq 99.8 \%$, Wako), tetrahydrofuran ( $\geq 99.8 \%$, stabilizer free, Wako), $\mathrm{D}_{2} \mathrm{O}$

136 (> 99.9 atom \% D, Sigma-Aldrich), $\mathrm{H}_{2}{ }^{18} \mathrm{O}(\geq 97 \%$, Cambridge Isotope Laboratories), $\mathrm{NaCl}(\geq$ $13799.999 \%$, Sigma-Aldrich) and $\mathrm{HCl}$ (37\%, ACS reagent, Sigma-Aldrich) were used as received.

\section{RESULTS AND DISCUSSION}

\section{Products of the Ozonolysis of $\alpha$-Pinene in Water:Acetonitrile Mixtures}

140 The products of the ozonolysis of $\alpha-P$ appear as negative ions in the online ESI mass spectra

141 of $\left(1 \mathrm{mM} \alpha-\mathrm{P}+0.2 \mathrm{mM} \mathrm{NaCl}+\left[\mathrm{O}_{3}\right]_{0}=0.03 \mathrm{mM}\right)$ solutions in W:AN (50:50 v:v; $\left.\left[\mathrm{H}_{2} \mathrm{O}\right]=27.8 \mathrm{M}\right)$ 142 mixtures (Fig. 1). 


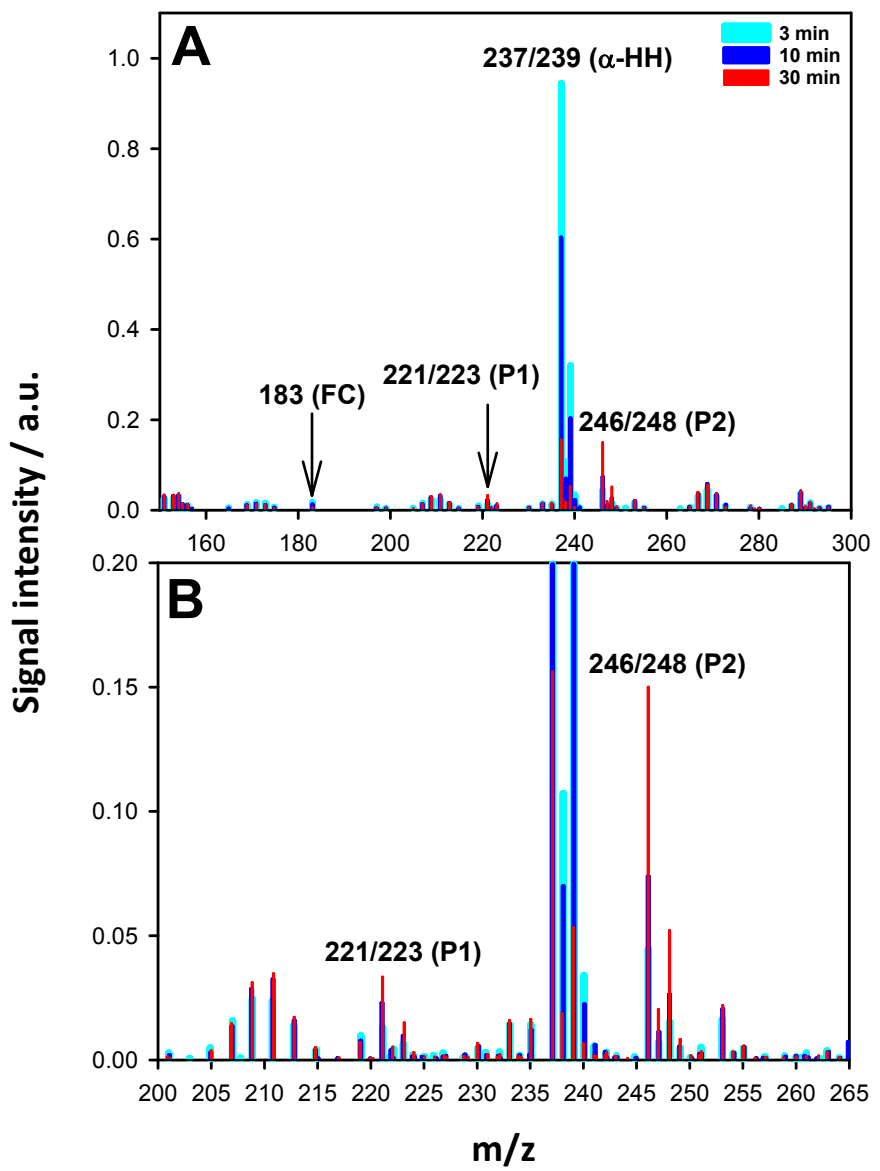

145 Figure $1-\mathrm{A})$ Negative ion ESI mass spectra of $\left(1 \mathrm{mM} \alpha\right.$-pinene $\left.+0.2 \mathrm{mM} \mathrm{NaCl}+\left[\mathrm{O}_{3}\right]_{0}=0.03 \mathrm{mM}\right)$ in W:AN 146 (50:50 by volume) at various times. B) Zooming-in on later-generated products. P1 and P2 correspond to 147 the chloride-adducts of a gem-diol and a hydroperoxide-cyanohydrin, respectively. FC stands for 148 functionalized carboxylate. See the text for details.

$\mathrm{O}_{3}$ should be consumed by excess $\alpha-P$ in a few milliseconds upon mixing $2.5 \mathrm{~mL}$ each of the $(2 \mathrm{mM} \alpha-P+0.4 \mathrm{mM} \mathrm{NaCl})$ and $0.06 \mathrm{mM} \mathrm{O}_{3}$ solutions. Our estimate is based on assuming 152 that the reaction rate constants in the gas and liquid phases have similar values, i.e.: $k(\alpha-P+$ $\left.\mathrm{O}_{3}\right)_{\text {liquid }} \approx 6.0 \times 10^{4} \mathrm{M}^{-1} \mathrm{~s}^{-1}$, from $k\left(\alpha-\mathrm{P}+\mathrm{O}_{3}\right)_{\text {gas }}=1.0 \times 10^{-16} \mathrm{~cm}^{3}$ molecule ${ }^{-1} \mathrm{~s}^{-1} .{ }^{45}$ Hence, $\mathrm{O}_{3}$

154 should decay within $\tau_{1 / \mathrm{e}} \sim 17$ milliseconds in $[\alpha-\mathrm{P}]=1 \mathrm{mM}$ solutions. Based on previous studies, ${ }^{46}$ we propose that $\mathrm{O}_{3}$ adds to the $\alpha-\mathrm{PC}=\mathrm{C}$ double bond producing a primary ozonide, ${ }^{47}$ which opens up into a carbonyl and (in condensed phases) a stabilized $\mathrm{Cl}$ (Scheme 2). The $\mathrm{Cl}$ is expected to rapidly isomerize into a functionalized carboxylic acid (detected as a 


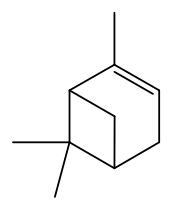

$\alpha$-Pinene (MW 136)

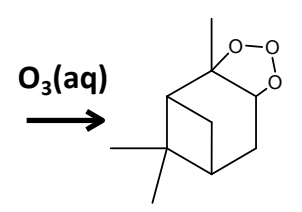

Primary ozonide (MW 184)

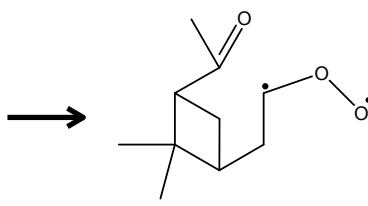

Criegee intermediate (Cl, MW 184)

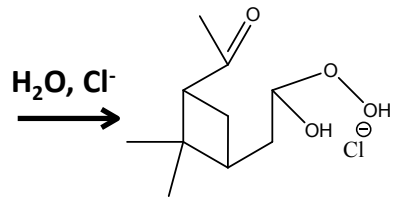

$\alpha$-Pinene $\alpha$-hydroxyalkyl-hydroperoxide (m/z 237/239)

The intense peaks at $\mathrm{m} / \mathrm{z} 237 / 239$ are therefore assigned to the chloride-adducts of the $\alpha-\mathrm{HH}: 237 / 239=136(\alpha-\mathrm{P})+48\left(\mathrm{O}_{3}\right)+18\left(\mathrm{H}_{2} \mathrm{O}\right)+35 / 37\left(\mathrm{Cl}^{-}\right)$, in line with previous experiments from our laboratory. ${ }^{44}$ The substitution of $\mathrm{D}_{2} \mathrm{O}$ and $\mathrm{H}_{2}{ }^{18} \mathrm{O}$ for $\mathrm{H}_{2}{ }^{16} \mathrm{O}$ and the addition of an $\mathrm{OH}$ radical scavenger support the assigned stoichiometries (see below). Establishing their molecular structures would require tandem mass spectrometric studies. The presence of chloride in the $\mathrm{m} / \mathrm{z} 237 / 239$ and other species is revealed by the characteristic 3-to-1 ratio of $237 / 239$ signal intensities, which corresponds to the ratio of natural abundance ${ }^{35} \mathrm{Cl} /{ }^{37} \mathrm{Cl}$ chlorine isotopes. We also detect species at m/z 221/223 (P1) and 246/248 (P2) (see below) at longer reaction times (Fig. 1B). Qualitatively similar results were obtained in the ozonolysis of the monoterpenes $d$-L and $\gamma$-Tn (see Figs. S2-S6, Schemes S1 and S2). It should be emphasized that the absence of commercially available samples of $\alpha-\mathrm{HH}$ and the products of

176 its decomposition precluded determining their relative response factors and, hence, establishing mass balances from measured mass signal intensities. scavenger, $\left.k_{\mathrm{OH}+\mathrm{THF}}=2.1 \times 10^{9} \mathrm{M}^{-1} \mathrm{~s}^{-1}\right)^{49}$ in reaction mixtures has negligible effects on the extent of reaction or the products distribution: the same product signals appear at $\mathrm{m} / \mathrm{z} 237 / 239$ ( $\alpha$ - 
181

182

183

184

185

186

187

188

189

190

191

192

193

194

195

196

197

198

199

200

201

202

$\mathrm{HH}), \mathrm{m} / \mathrm{z} 221 / 223$ (P1) and 246/248 (P2) (Fig. S7). This finding excludes the significant participation of $\mathrm{OH}$-radicals in the formation or destruction of these species. ${ }^{50}$

\section{Products of the Ozonolysis of $\alpha$-Pinene in $\mathrm{D}_{2} \mathrm{O}$ :Acetonitrile and $\mathrm{H}_{2}{ }^{18} \mathrm{O}$ :Acetonitrile Mixtures}

The shifts of mass signals in $\mathrm{D}_{2} \mathrm{O}: \mathrm{AN}$ and $\mathrm{H}_{2}{ }^{18} \mathrm{O}$ :AN solutions are consistent with the proposed mechanism of $\alpha-\mathrm{HH}$ formation (Scheme 2) and decomposition (Scheme 3). The fact that the $m / z=237 / 239$ signals shift by +2 mass units to $m / z 239 / 241$ in both $D_{2} O: A N$ and $\mathrm{H}_{2}{ }^{18} \mathrm{O}$ :AN (Figs. S8 and S9) confirms the participation of one water molecule in the formation of the $\alpha-\mathrm{HH}$. A second water molecule substitutes an $-\mathrm{O}-\mathrm{H}$ group for the $-\mathrm{O}-\mathrm{O}-\mathrm{H}$ functionality by eliminating $\mathrm{H}_{2} \mathrm{O}_{2}$ and producing an aldehyde whose gem-diol can exchange two O-atoms via a keto $\rightleftharpoons$ gem-diol equilibrium (Scheme 3). This is confirmed by the finding that the P1 (m/z 221/223) signals shift by +2 Da to $m / z$ 223/225 in $D_{2} \mathrm{O}: A N$ (Fig. $S 8$ ), and by +4 Da to $\mathrm{m} / \mathrm{z}$ 225/227 in $\mathrm{H}_{2}{ }^{18} \mathrm{O}$ :AN (Fig. S9). We infer that $\alpha-\mathrm{HH}$ decomposes by reacting with water via reaction $\mathrm{R} 1$,

$$
\alpha-\mathrm{HH}+2 \mathrm{H}_{2} \mathrm{O} \rightarrow \text { gem-diol }(\mathrm{P} 1)+\mathrm{H}_{2} \mathrm{O}_{2}
$$

Scheme 3. Mechanism of $\alpha$-Pinene $\alpha$-Hydroxyalkyl-Hydroperoxide Reaction with Water a

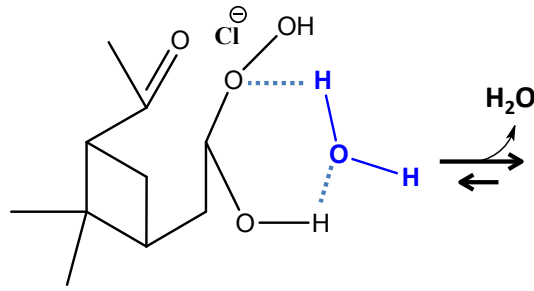

$\alpha$-Hydroxyalkyl-hydroperoxide

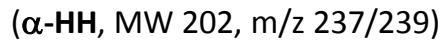<smiles>CC(=O)CC1CCC(=O)C1(C)C</smiles>

Functionalized aldehyde (MW 168)

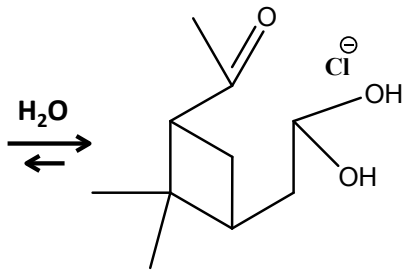

Functionalized gem-diol (P1, MW 186, m/z 221/223)

\footnotetext{
${ }^{a}$ Shown are what we consider the most likely among isomers.
}

The P2 m/z 246/248 even mass signals clearly correspond to a species containing one $\mathrm{N}$ atom. The molecular formula of P2 corresponds to the chloride-adduct of the cyanohydrin 
resulting from the addition of $\mathrm{HCN}$ (an impurity from the partial hydrolysis of $A N$ in W:AN mixtures) to an intermediate species derived from a fast $\mathrm{Cl}$ isomerization channel: ${ }^{51,52} \mathrm{~m} / \mathrm{z}=$ $136(\alpha-P)+48\left(\mathrm{O}_{3}\right)+27(\mathrm{HCN})+35 / 37\left(\mathrm{Cl}^{-}\right)=246 / 248$. We tentatively assign to such intermediate a vinyl-hydroperoxide (Scheme S3). The putative vinyl-hydroperoxide intermediate, by having a single $-\mathrm{OOH}$ group (such as TBHP and $\mathrm{CHP}$, see above), is not expected to form a $\mathrm{Cl}^{-}$-adduct. The reasoning behind this assignment is that the delayed formation of P2 (see Figs. 1 B and 3) implies that HCN does not compete with water for the $\mathrm{Cl}$, but rather reacts with a species simultaneously produced with the formation of the $\alpha-\mathrm{HH}$ (Scheme S3). A P2 cyanohydrin containing $-\mathrm{OH}$ and $-\mathrm{OOH}$ groups that can exchange protons for deuterons accounts for the +2 Da shifts undergone by the $246 / 248$ signals in $\mathrm{D}_{2} \mathrm{O}: \mathrm{AN}$ (Fig. S8). The +2 Da shifts in $\mathrm{H}_{2}{ }^{18} \mathrm{O}$ :AN mixtures are tentatively ascribed to O-atom exchange between $\mathrm{H}_{2}{ }^{18} \mathrm{O}$ and the carbonyl O-atom of the vinyl-hydroperoxide (Fig. S9). We note that $\mathrm{HCN}$ does not add to the carbonyl group of the $\alpha-\mathrm{HH}$ (a reaction that would have produced a species appearing at $\mathrm{m} / \mathrm{z} 264 / 268$ ), possibly because the carbonyl is blocked by intramolecular hydrogen bonding with the $-\mathrm{C}(-\mathrm{OH})(-\mathrm{OOH})$ group.

\section{Products of the Ozonolysis of $\alpha$-Terpineol in Water and Water:Acetonitrile Mixtures}

Negative ion mass spectra as functions of time in the ozonolysis of $(\alpha-\mathrm{Tp}+\mathrm{NaCl})$ in $100 \%$ W and W:AN (50:50) mixtures are shown in Fig. 2. The intense peaks at m/z 255/257 are ascribed to the chloride-adducts of the $\alpha-\mathrm{Tp} \alpha-\mathrm{HH}: 255 / 257=154(\alpha-\mathrm{Tp})+48\left(\mathrm{O}_{3}\right)+18\left(\mathrm{H}_{2} \mathrm{O}\right)$ $+35 / 37\left(\mathrm{Cl}^{-}\right)$(Scheme 4), in line with results for the ozonolysis of $\alpha-\mathrm{Tp}$ at the air-water interface. ${ }^{53}$ The presence of a hydroperoxide-cyanohydrin, detected as a chloride-adduct at $m / z=264 / 266=154(\alpha-T p)+48\left(\mathrm{O}_{3}\right)+27(\mathrm{HCN})+35 / 37\left(\mathrm{Cl}^{-}\right)$, in W:AN (50:50) (Fig. 2B), and its absence in pure W (Fig. 2A) confirms that $\mathrm{HCN}$ originates from the partial hydrolysis of $\mathrm{AN}$ in W:AN mixtures. 


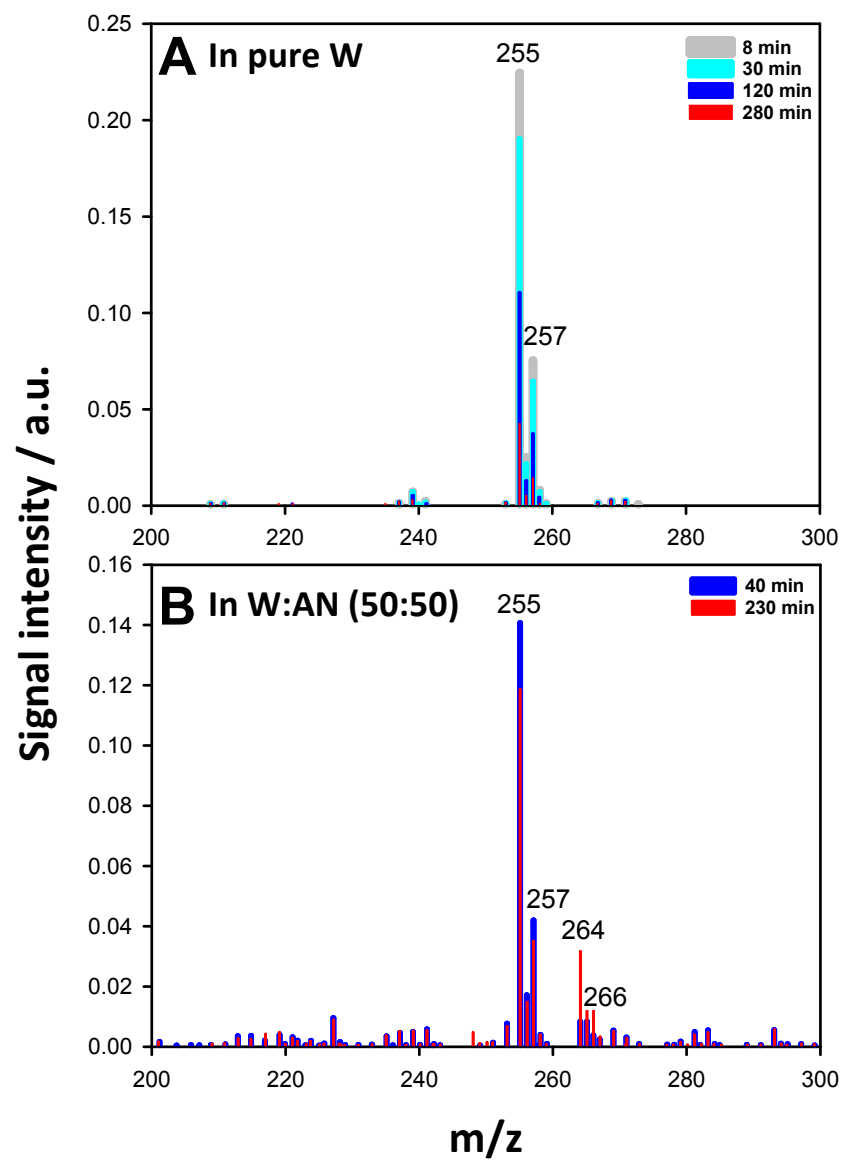

Figure $2-A)$ Negative ion mass spectra of $1 \mathrm{mM} \alpha$-terpineol $+0.2 \mathrm{mM} \mathrm{NaCl}+\left[\mathrm{O}_{3}\right]_{0} \approx 0.04 \mathrm{mM}$ in neat water, B) in a W:AN (50:50) mixture, at various times.

Scheme 4. Mechanism of the Ozonolysis of $\alpha$-Terpineol in Water:Acetonitrile a
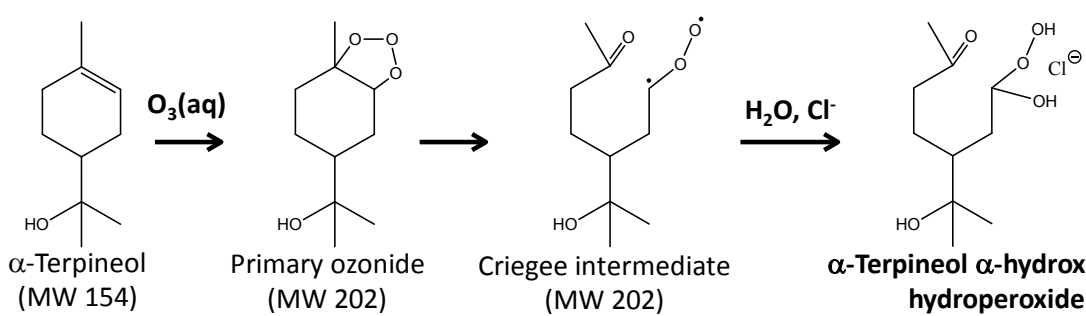

(MW 154) (MW 202) (MW 202)

$$
\text { hydroperoxide }
$$
(m/z 255/257)
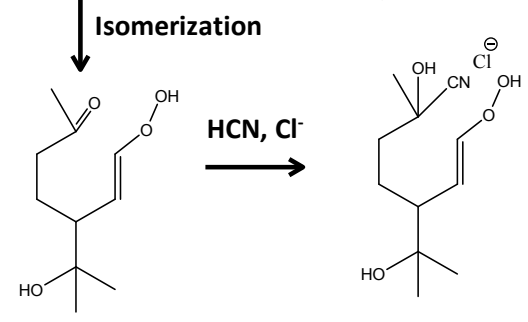

Vinyl-hydroperoxide (MW 202)

$\alpha$-Terpineol hydroperoxide-

${ }^{a}$ Shown are what we consider the most likely among isomers 


\section{Kinetic Experiments}

The temporal profiles of the detected products of $\alpha$-P ozonolysis, namely the $\alpha-\mathrm{HH}(\mathrm{m} / \mathrm{z}$ 237/239), P1 (m/z 221/223) and P2 (m/z 246/248), in W:AN (50:50, [W] = $27.8 \mathrm{M}$ and 20:80, $[\mathrm{W}]=11.1 \mathrm{M})$ are shown in Figures $3 \mathrm{~A}$ and $\mathrm{B}$. In both mixtures, $\alpha-\mathrm{HH}(\mathrm{m} / \mathrm{z} 237 / 239)$ signals decay as single-exponentials (see below) with rate coefficients: $k_{1}(20: 80)=(2.7 \pm 1.7) \times 10^{-4}$ $\mathrm{s}^{-1}$ and $k_{1}(50: 50)=(1.1 \pm 0.1) \times 10^{-3} \mathrm{~s}^{-1}$, the averages of four independent runs. These $k_{1}$ values correspond to $\tau_{1 / \mathrm{e}}=62 \mathrm{~min}$ and $15 \mathrm{~min}$, respectively. The rate coefficients determined in the present study are summarized in Table 1. In similar experiments, we had found that the $\alpha-\mathrm{HH}$ from the ozonolysis of $\beta$-caryophyllene (50:50) mixtures decayed in $\tau_{1 / \mathrm{e}}=52 \mathrm{~min} .{ }^{25}$ Inspection of the data in Table 1 and Figure 4 shows that the decay of $\alpha-\mathrm{P} \alpha-\mathrm{HH}$ becomes significantly slower in solvent mixtures of lower water content. The dependence of $k_{1}$ on water content, however, is not linear as it would be expected from water as a reactant in R1. Remarkably, while $\tau_{1 / \mathrm{e}}=52 \mathrm{~min}$ in $30 \%$ water slightly increases to $\tau_{1 / \mathrm{e}}=62 \mathrm{~min}$ in $20 \%$ water, the decay of $\alpha-\mathrm{HH}$ in $10 \%$ water is dramatically different. In the $10 \%$ water mixture, $\alpha-\mathrm{HH}$ decays by $~ 35 \%$ in the first 15 min followed by a much slower decay that extends for hours (Figure S11).

It should be realized that if water molecules were homogeneously mixed the molecular level, the decay of $\alpha-\mathrm{HH}$ would be single-exponential function because water participates as a reagent in both the consecutive reactions in Scheme 3. The decay of $\alpha-\mathrm{HH}$ signal intensities (S) in (10:90) mixtures is well represented by a bi-exponential function: $S=S_{01} \exp \left(-k_{1} t\right)+S_{02}$ $\exp \left(-k_{2} t\right)$ (Fig. S11), with $\tau_{1 / \mathrm{e}}=1 / k_{2}=641 \mathrm{~min}$ (Table 1 ). The observed fast and slow regimes may be indicative of the availability of water to $\alpha-\mathrm{HHs}$ in W:AN water-rich and water-poor domains of molecular dimensions (see below). The $\alpha$-HHs from $d$-L and $\beta$-caryophyllene display a similar behavior in (20:80) and (10:90) mixtures. $^{25}$ 


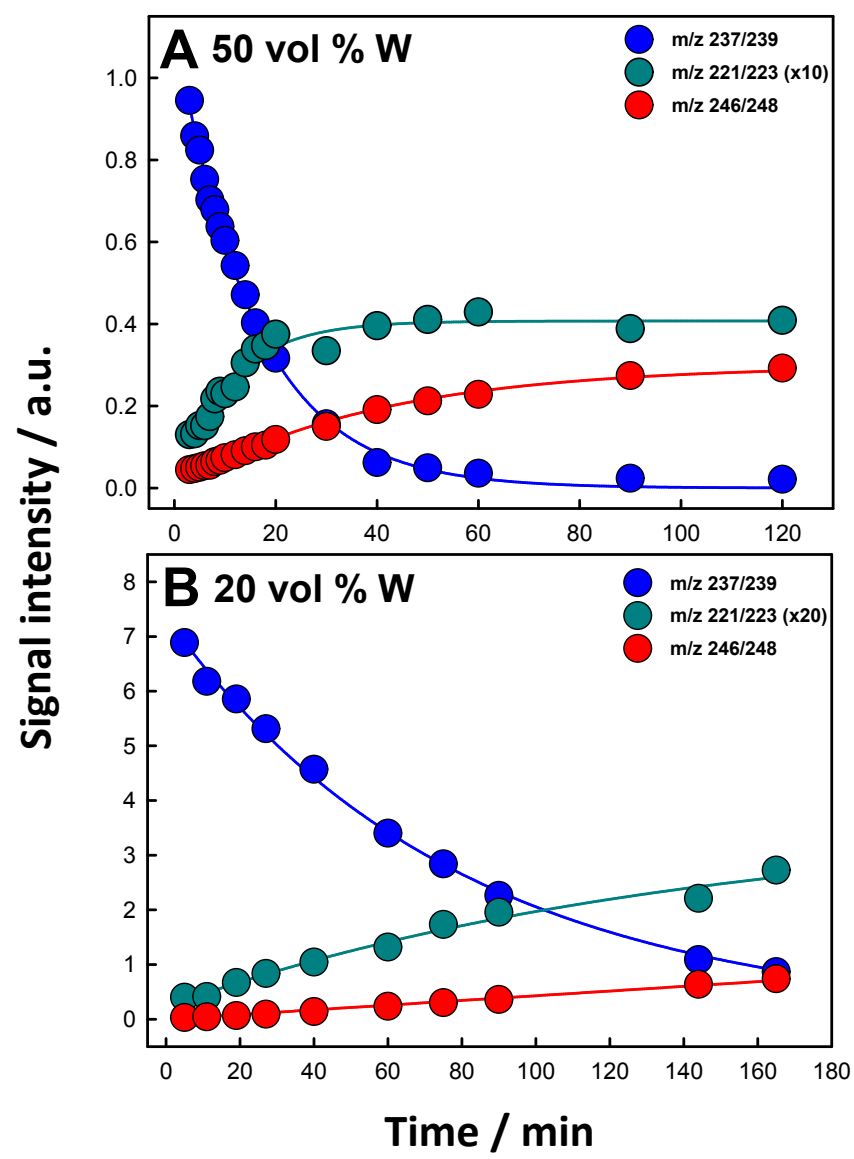

Figure 3 - Temporal profiles of the chloride-adducts of the products of $\alpha$-pinene ozonolysis of ( $1 \mathrm{mM} \alpha$ pinene, $\left.1 \mathrm{mM} \mathrm{NaCl},\left[\mathrm{O}_{3}\right]_{0}=0.05 \mathrm{mM}\right)$ in A: (50:50), B: (20:80) W:AN mixtures. Blue: $\alpha-\mathrm{HH}(\mathrm{m} / \mathrm{z} 237 / 239)$; dark cyan: P1 (m/z 221/223); red: P2 (m/z 246/248). P1 signal intensities were multiplied by 10 (A) and 20 (B), respectively. Lines correspond to fitting signal intensities $(S)$ vs time with: $S=S_{0} \exp \left(-k_{1} t\right)$ or $S=S_{\max }[1-$ $\exp (-k t)]$ functions. See text for details. 


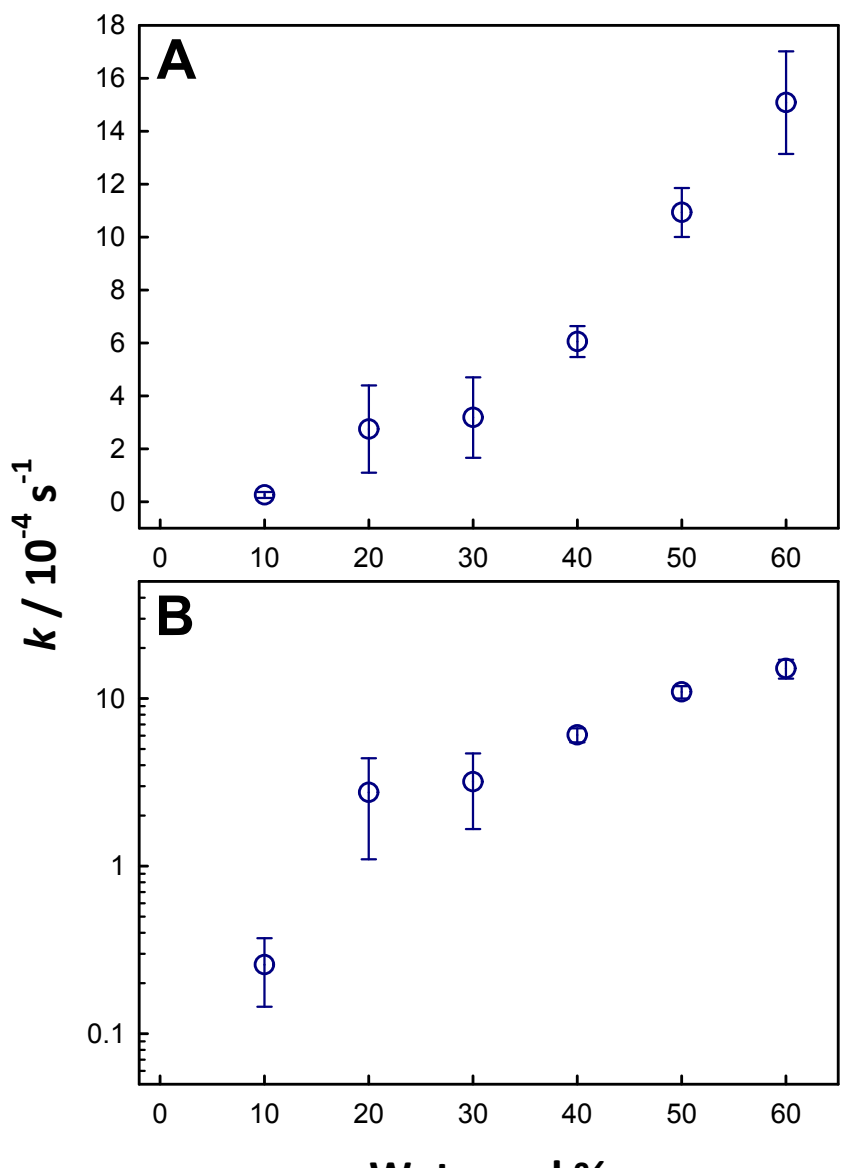
Figure $4-$ A) First-order rate coefficients $k_{1}$ of the decay of the chloride-adduct of $\alpha$-pinene $\alpha-\mathrm{HH}(\mathrm{m} / \mathrm{z}$ 237/239) in W:AN mixtures as a function of water volume, at $298 \pm 3 \mathrm{~K}$. Data from Table 1. $k_{1}$ values derived by fitting $\alpha-H H$ signal intensities (S) vs time with: $S=S_{0} \exp \left(-k_{1} t\right)$, except in the case of the $10 \%$ W mixture where the plotted value is $k_{2}$ from: $S=S_{01} \exp \left(-k_{1} t\right)+S_{02} \exp \left(-k_{2} t\right)$, fits. See text for details. Error bars are derived from 3-4 independent measurements. B) The semi-log plot shows the dramatic increase of $\alpha-\mathrm{HH}$ persistence in $10 \% \mathrm{~W}$. 
Table 1- Rate Coefficients of $\alpha$-HHs Decay in Water:Acetonitrile Mixtures vs Water vol $\%$ at $298 \pm 3 \mathrm{~K}$

280

281

282

283

284

285

286

287

288

289

290

291

292

293

294

\begin{tabular}{|c|c|c|c|}
\hline Terpene & Water (volume \%) & $k\left(10^{-4} \mathrm{~s}^{-1}\right)^{\mathrm{a}}$ & $\tau_{1 / \mathrm{e}}$ (minutes) \\
\hline \multirow[t]{6}{*}{$\alpha$-Pinene } & 10 & $0.26 \pm 0.11 *$ & 641 \\
\hline & 20 & $2.7 \pm 1.7$ & 62 \\
\hline & 30 & $3.2 \pm 1.5$ & 52 \\
\hline & 40 & $6.1 \pm 0.6$ & 27 \\
\hline & 50 & $11 \pm 1$ & 15 \\
\hline & 60 & $12 \pm 2$ & 14 \\
\hline \multirow[t]{2}{*}{$d$-Limonene } & 20 & $1.3 \pm 1.0^{*}$ & 128 \\
\hline & 50 & $12 \pm 3$ & 14 \\
\hline \multirow[t]{2}{*}{$\gamma$-Terpinene } & 20 & $0.48 \pm 0.29$ & 347 \\
\hline & 50 & $3.7 \pm 1.5$ & 45 \\
\hline \multirow[t]{3}{*}{$\alpha$-Terpineol } & 50 & $0.16 \pm 0.01$ & 1042 \\
\hline & 100 & $1.3 \pm 0.4$ & 128 \\
\hline & $100^{b}$ & $1.0 \pm 0.1$ & 167 \\
\hline \multirow[t]{5}{*}{$\beta$-Caryophyllene ${ }^{c}$} & 10 & $0.031 \pm 0.002 *$ & 5376 \\
\hline & 20 & $1.4 \pm 0.6$ & 119 \\
\hline & 30 & $1.4 \pm 0.2$ & 119 \\
\hline & 40 & $1.7 \pm 0.4$ & 98 \\
\hline & 50 & $3.2 \pm 0.7$ & 52 \\
\hline
\end{tabular}

295

aRate coefficients are $k_{1}$ values derived from experimental $\alpha-\mathrm{HH}$ signal intensities (S) fits by singleexponential decay functions: $S=S_{01} \exp \left(-k_{1} t\right)$ functions $\left(\tau_{1 / \mathrm{e}}=1 / k_{1}\right)$, except those marked with an asterisk $(*)$, which correspond to $k_{2}$ for the slower component of the observed bi-exponential decays: $S=S_{01} \exp (-$ $\left.k_{1} t\right)+S_{02} \exp \left(-k_{2} t\right)\left(\tau_{1 / \mathrm{e}}=1 / k_{2}\right)^{b}$ In the presence of $1 \mu \mathrm{M} \mathrm{FeCl}_{2} .{ }^{\mathrm{c}}$ From reference 25 . See text for details.

299

We also analyzed the rise of product signal intensities with time. The evolution of $\mathrm{P} 1 \mathrm{(m} / \mathrm{z}$ $221 / 223$ ) signal intensities with time (Fig. 3) in $\alpha$-P experiments is well fitted by: $S=S_{\max }[1-$ $\left.\exp \left(-k_{\mathrm{P} 1} \mathrm{t}\right)\right]$ functions. Four independent measurements led to $k_{\mathrm{P} 1}=(1.6 \pm 0.2) \times 10^{-3} \mathrm{~s}^{-1}$ in

303 (50:50) mixtures, and $k_{\mathrm{P} 1}(2.0 \pm 0.2) \times 10^{-4} \mathrm{~s}^{-1}$, in (20:80) mixtures. These values compare well with the $k_{1}=(1.1 \pm 0.1) \times 10^{-3}$ and $(2.7 \pm 1.7) \times 10^{-4} \mathrm{~s}^{-1}$ values for $\alpha-\mathrm{HH}$ decays in the same mixtures, confirming that $\mathrm{P} 1$ is a direct product of $\alpha-\mathrm{HH}$ decomposition. Based on this result and the $\mathrm{P} 1$ mass shifts in $\mathrm{D}_{2} \mathrm{O}: \mathrm{AN}$ and $\mathrm{H}_{2}{ }^{18} \mathrm{O}: \mathrm{AN}$ experiments, we assign $\mathrm{P} 1$ to the $[1-(3-(2,2-$ 
dihydroxyethyl)-2,2-dimethylcyclobutyl) ethenone] gem-diol produced from the substitution of an $-\mathrm{OH}$ for the $-\mathrm{OOH}$ group in $\alpha-\mathrm{HH}$ (Scheme 3). Because $\alpha-\mathrm{HH}$ signals decay to zero in all cases, except in $10 \%$ water, the equilibrium: $\alpha-\mathrm{HH}=\mathrm{P} 1+\mathrm{H}_{2} \mathrm{O}_{2}$, is fully shifted to the products side (Scheme 3). ${ }^{54}$ In contrast, the rise P2 (m/z 246/248) signal intensities in (50:50) mixtures: $\mathrm{S}=\mathrm{S}_{\max }\left[1-\exp \left(-k_{\mathrm{P} 2} \mathrm{t}\right)\right]$, corresponds to $k_{\mathrm{P} 2}=(4.2 \pm 0.3) \times 10^{-4} \mathrm{~s}^{-1}$. This value is about four times smaller than $k_{1}$ indicating that P2 is not a product of $\alpha-\mathrm{HH}$ decomposition (Scheme 4).

To recapitulate, the data of Table 1 reveal that in (50:50) mixtures the $\alpha-\mathrm{HH}$ from $\alpha-\mathrm{P}$ and $d$ - $\mathrm{L}$ decompose into $\mathrm{H}_{2} \mathrm{O}_{2}$ at comparable rates, which are $\sim 3$ times faster than the $\alpha-\mathrm{HH}$ from $\gamma$-Tn, and $\sim 70$ times faster than that from $\alpha$-Tp. Decay rates markedly increase in a nonlinear manner with water content. The $\alpha-H H$ from $\alpha-P$, the most abundant biogenic monoterpene in the atmosphere, lasts from tens of minutes in $>20 \%$ water mixtures to $\sim 9$ hours in $\leq 10 \%$ water. Below we show that the rapid conversion of $\alpha-\mathrm{HH}$ to $\mathrm{H}_{2} \mathrm{O}_{2}$ in SOA under atmospheric conditions may preempt its decomposition into free radicals via solar photolysis $^{22,55}$ or catalyzed by transition metal ions. ${ }^{29,30}$

We analyze the physicochemical underpinnings of these findings, and their potential implications for the fate and quantification of hydroperoxides in SOA. In the case of $\alpha-P$, the strong non-linear dependence on water content of the rate constants ( $k_{1}$ or $k_{2}$, see above) for the $\alpha-\mathrm{HH}+\mathrm{H}_{2} \mathrm{O}$ reaction (Fig. 4) implies that $\mathrm{H}_{2} \mathrm{O}$ is not directly accessible to the $\alpha-\mathrm{HH}$ in these solvent mixtures. We had observed a similar non-linear behavior in the decay of the $\alpha-\mathrm{HH}$ produced from the ozonolysis of $\beta$-caryophyllene. ${ }^{25,56}$ We propose that this is evidence that $\alpha-\mathrm{HHs}$ are produced in discrete domains where water accessibility depends on their structure and water exchange dynamics, rather than in homogeneous media.

These domains are generally present in mixtures of water with miscible organic solvents. ${ }^{57-59}$ This is substantiated by small-angle neutron and dynamic light scattering experiments detect short-lived $(<50 \mathrm{ps})$, short-ranged $(\sim 1 \mathrm{~nm})$ concentration fluctuations in 
most water-hydrotrope mixtures, ${ }^{58-60}$ and with recent reactivity and selectivity studies of reactions in these media. ${ }^{57,59}$ A recent soft X-ray absorption spectroscopic study of W:AN mixtures presented evidence of microheterogeneity. ${ }^{61} \mathrm{Ab}$-initio quantum chemical innershell calculations suggested that the three distinct regions observed in these mixtures result from the interplay of hydrogen bonding and dipolar interactions between water and acetonitrile molecules. ${ }^{61}$ Notably, the discontinuity observed at $\approx 13$ vol \% W (molar fraction of water $x_{w}=0.3$ ) was ascribed to a transition between phases mainly containing AN-rich large $\mathrm{W}_{\mathrm{n}} \mathrm{AN}_{\mathrm{m}}$ clusters below $x_{w}=0.3$ and smaller clusters held by dipolar interactions above $x_{w}=$ 0.3. ${ }^{61}$ We believe that the dramatic increase of $\alpha-\mathrm{HH}$ persistence below $20 \mathrm{vol} \% \mathrm{~W}$ is associated with such phase-transition. Additional evidence is provided by the non-linear dependences of the intensity, peak emission wavelength, and decay lifetime of 7-cyanoindole fluorescence in W:AN and other eight W:hydrotope mixtures as functions of water molar fraction. ${ }^{62}$ The fact that 7-cyanoindole fluorescence in W:AN decayed as a single exponential in the 2-12 ns range, indicated that 7-cyanoindole fluoresced while embedded in the most abundant $\mathrm{W}_{\mathrm{n}} \mathrm{AN}_{\mathrm{m}}$ clusters of the $(n, m)$ distribution.

Against this backdrop, our results suggest that $\alpha-\mathrm{HHs}$ (reaction R1) are generated in situ from the ozonolysis of monoterpenes embedded in $\mathrm{W}_{n} \mathrm{AN}_{\mathrm{m}}$ clusters rather than dissolved in molecularly homogeneous solutions. The accessibility of $\mathrm{H}_{2} \mathrm{O}$ to $\alpha-\mathrm{HHs}$ should depend on the composition and rearrangement dynamics of $\mathrm{W}_{n} \mathrm{AN}_{\mathrm{m}}$ clusters rather than on the macroscopic concentration of water. In such scenario, the limited rapid initial decay of $\alpha$-HHs followed by a much slower process in (10:90) mixtures may reflect the $(n, m)$ distribution of $\mathrm{W}_{\mathrm{n}} \mathrm{AN}_{\mathrm{m}}$ clusters. In (10:90) mixtures, only a few clusters would contain a significant number of water molecules, those accounting for the fast $\alpha-\mathrm{HH}$ decay. Since microheterogeneity should be a general phenomenon in "internally mixed" aqueous organic mixtures, we suggest that the existence of inhomogeneities at the molecular level, as distinct from mesoscopic 
segregation, ${ }^{63-65}$ could play unanticipated roles in atmospheric aqueous media. ${ }^{56}$

The relatively short lifetimes of the $\alpha-\mathrm{HHs}$ derived from the ozonolysis of monoterpenes relative to the dramatic persistence of the $\alpha-\mathrm{HH}$ derived from $\alpha-\operatorname{Tp}$ (Table 1 and Fig. S12) is another unanticipated outcome, because it is difficult to envision a long-range intramolecular effect (through four bonds) of the $-\mathrm{OH}$ group on the reactivity of the $\mathrm{R}-(\mathrm{H}) \mathrm{C}(-\mathrm{OH})(-\mathrm{OOH})$ group. Even in pure $\mathrm{W}$, the $\alpha$-Tp-derived $\alpha-\mathrm{HH}$ survives for over 2 hours. One possibility is that water molecules bridge $-\mathrm{OH}$ and $-\mathrm{OOH}$ groups via extended hydrogen-bonding, thereby blocking the formation of the six-membered transition state for to $\alpha-\mathrm{HH}$ decomposition into aldehyde $+\mathrm{H}_{2} \mathrm{O}_{2}$ (Scheme 1). Another possibility involves an orientation effect whereby the polar exo-OH group of $\alpha-\mathrm{Tp}$ forces the hydrophobic backbone containing the endo $\mathrm{C}=\mathrm{C}$ bond (and, as a result the $\mathrm{R}-(\mathrm{H}) \mathrm{C}(-\mathrm{OOH})(-\mathrm{OH})$ group) to $\mathrm{AN}$-rich cluster cores in $\mathrm{W}$ :AN mixtures. ${ }^{61}$

pH Effects on the Decay Rates of $\alpha$-Tp-derived $\alpha$-HH in Pure Water additions) on the kinetics of decomposition of $\alpha$-Tp-derived $\alpha$-HH in pure water. The results are shown in Table 2.

Table 2- Rate Coefficients of $\alpha$-Tp-derived $\alpha$-HHs Decay in Water vs pH at $[\alpha-T p]_{0}=1$ $\mathrm{mM},\left[\mathrm{O}_{3}\right]_{0}=0.06 \mathrm{mM}$ at $298 \pm 3 \mathrm{~K}$.

\begin{tabular}{|c|c|c|c|}
\hline$\alpha$-Terpineol & $\mathbf{p H}$ & $\boldsymbol{K}_{\mathbf{1}}\left(\mathbf{1 0}^{-\mathbf{4}} \mathbf{s}^{-\mathbf{1}}\right)$ & $\tau_{1 / \mathrm{e}}$ (minutes) $^{\mathrm{a}}$ \\
\hline & 2.3 & $8.7 \pm 1.0$ & 19 \\
& 2.6 & $4.4+0.5$ & 38 \\
& 3.0 & $3.0 \pm 0.2$ & 56 \\
& 3.3 & $2.5 \pm 0.2$ & 66 \\
& 6.1 (as is) & $1.3 \pm 0.4$ & 128 \\
\hline
\end{tabular}


catalyzed reaction. This is an important effect, considering that ambient cloud water and aqueous aerosols are more acidic than previously assumed. ${ }^{66-68}$ This finding is in contrast with the opposite $\mathrm{pH}$ effect reported for the decomposition of $\alpha$-acyloxyalkyl-hydroperoxides, produced from $\alpha-\mathrm{P}^{\prime} \mathrm{s}$ Cls reactions with pinonic and adipic acids. ${ }^{40} \mathrm{Zhao}$ et al. reported the linear increase in the first-order decay rate coefficient as $\mathrm{pH}$ increased from 3.5 to 5.1 , which is consistent with an $\mathrm{OH}^{-}$catalyzed decomposition. ${ }^{40}$ The different behaviors may be ascribed to the key role played by the $\alpha-\mathrm{OH}$ group in $\mathrm{R}(-\mathrm{H})(-\mathrm{OH})(-\mathrm{OOH})$ decomposition, which is absent in $\alpha$-acyloxyalkyl-hydroperoxides $\mathrm{R}(-\mathrm{H})(-\mathrm{OR})(-\mathrm{OOH})$.

\section{Atmospheric Implications}

The fast decomposition of monoterpene-derived $\alpha$-HHs, e.g., $\tau_{1 / \mathrm{e}} \sim 15 \mathrm{~min}$ in $50 \mathrm{vol} \%$ water, suggests that significant losses may occur prior to off-line chemical analyses of SOA samples whether collected in the field or synthesized in the laboratory. ${ }^{39,} 40,69$ We suggest that discordant results obtained under otherwise similar conditions could be due to variations of depending on relative humidity or water content, to the non-linear dependence of $k_{1}$ on water content, and to the onset of the much slower component of bi-exponential decays in < $20 \%$ water media.

Regarding the role of $\alpha-\mathrm{HH}$ in SOA aging, our findings reveal that their decomposition does not yield free radicals but $\mathrm{H}_{2} \mathrm{O}_{2}$ via reaction R1. R1 preserves the peroxide content and, therefore, the potential toxicity of SOA. ${ }^{50,70,71}$ Regarding the putative role of free radicals in SOA aging from the decomposition of $\mathrm{RC}-\mathrm{OOH}$ hydroperoxides, we point out that thermal decomposition studies in dilute solutions have shown that the homolysis of $\mathrm{RO}-\mathrm{OH}$ bonds proceeds with $\tau_{1 / 2}=10 \mathrm{~h}$ half-lives at temperatures above $130^{\circ} \mathrm{C} .{ }^{18}$ In other words, neither RC$\mathrm{OOH}$ hydroperoxides nor $\mathrm{R}-(\mathrm{H}) \mathrm{C}(-\mathrm{OH})(-\mathrm{OOH}) \quad \alpha$-hydroxyalkyl-hydroperoxides could conceivably produce free radicals in SOA at ambient temperatures. On the other hand, UVvisible spectra of $1 \mathrm{mM} \beta$-caryophyllene in W:AN (50:50) before and after ozonolysis (Fig. S13) 
show that the peak absorption of reaction products occurs at $\sim 280 \mathrm{~nm}$, which corresponds to carbonyl chromophores. Thus, the solar photolysis of $\alpha-\mathrm{HH}$ and their products will be dominated by carbonyl rather than peroxide photochemistry. ${ }^{22,72}$

Fenton-like chemistry is expected to take place in hours rather than in tens of minutes under typical conditions. ${ }^{22,55}$ From representative values of $\left[\mathrm{Fe}^{2+}\right] \sim 10^{-7} \mathrm{M},[\mathrm{ROOH}] \sim 10^{-6} \mathrm{M}$ in aqueous aerosol/cloud droplets, ${ }^{30,54}$ and $k\left(\mathrm{Fe}^{2+}+\mathrm{ROOH}\right) \sim 20 \mathrm{M}^{-1} \mathrm{~s}^{-1},{ }^{29}$ we estimate $\tau_{1 / \mathrm{e}}>$ $14 \mathrm{~h}$ for Fenton-like $\alpha$-HHs decompositions, which is much longer than the $\tau_{1 / \mathrm{e}}<1 \mathrm{~h}$ values derived from the data of Table 1. We confirmed the slowness of Fenton-like chemistry in the timeframe of our experiments by showing that the presence of catalytic concentrations of $\mathrm{Fe}^{2+}$ did not even accelerate the slow decay of the $\alpha-\mathrm{HH}$ derived from the ozonolysis of ( $1 \mathrm{mM}$ $\alpha-\mathrm{Tp}+0.2 \mathrm{mM} \mathrm{NaCl}+1 \mu \mathrm{M} \mathrm{FeCl}_{2}$ ) in neat water (Table 1).

In summary, we found that the $\alpha-\mathrm{HH}$ derived from the ozonolysis of atmospherically important monoterpenes react with water to produce $\left(\right.$ gem-diols $+\mathrm{H}_{2} \mathrm{O}_{2}$ ) rather than free radicals. $\alpha-\mathrm{HH}$ decay mono- or bi-exponentially depending on both molecular structure and solvent composition. $\tau_{1 / \mathrm{e}}$ in water-rich solvent mixtures range from $\tau_{1 / \mathrm{e}}=15-45 \mathrm{~min}$ for monoterpene-derived $\alpha$-HHs to $\tau_{1 / \mathrm{e}}>10^{3} \mathrm{~min}$ for the $\alpha$-Tp-derived $\alpha-\mathrm{HH}$. Remarkably, all $\tau_{1 / \mathrm{e}}$ 's dramatically increase in $<20 \%$ (v:v) water. The decomposition of the $\alpha$-Tp-derived $\alpha$ $\mathrm{HH}$ in pure water is accelerated at lower $\mathrm{pH}$ in the $\mathrm{pH} 2.3$ to 3.3 range. The residual hydroperoxides detected in day-old SOA samples may reflect the slower components of biexponential decays in water-poor media and/or the slow decomposition of $\alpha$-HHs from functionalized terpenes.

\section{Corresponding authors}

*Authors to whom correspondence should be addressed:
A.J.C. ajcoluss@caltech.edu, phone: +1-626-396-6350

S.E. enami.shinichi@nies.go.jp, phone: +81-29-850-2770

\section{ORCID}

Kenichi Tonokura: 0000-0003-1910-8508 
433 Agustín J. Colussi: 0000-0002-3400-4101

434 Shinichi Enami: 0000-0002-2790-7361

\section{Acknowledgements}

436 S. E. is grateful to the JSPS KAKENHI grant number 19H01154. A.J.C. acknowledges support 437 from the National Science Foundation USA, Grant AGS-1744353.

\section{SUPPORTING INFORMATION}

439 Additional experimental data.

\section{Author Contributions}

441 S.E. designed research; J.Q., Z.L. and S.E. performed experiments; S.E. contributed new 442 reagents/analytic tools; All authors analyzed data and wrote the paper. 
1. Ehn, M.; Thornton, J. A.; Kleist, E.; Sipila, M.; Junninen, H.; Pullinen, I.; Springer, M.; Rubach, F.; Tillmann, R.; Lee, B.; Lopez-Hilfiker, F.; Andres, S.; Acir, I. H.; Rissanen, M.; Jokinen, T.; Schobesberger, S.; Kangasluoma, J.; Kontkanen, J.; Nieminen, T.; Kurten, T.; Nielsen, L. B.; Jorgensen, S.; Kjaergaard, H. G.; Canagaratna, M.; Dal Maso, M.; Berndt, T.; Petaja, T.; Wahner, A.; Kerminen, V. M.; Kulmala, M.; Worsnop, D. R.; Wildt, J.; Mentel, T. F., A large source of lowvolatility secondary organic aerosol. Nature 2014, 506, (7489), 476-479. 2. Jokinen, T.; Berndt, T.; Makkonen, R.; Kerminen, V.-M.; Junninen, H.; Paasonen, P.; Stratmann, F.; Herrmann, H.; Guenther, A. B.; Worsnop, D. R., Production of extremely low volatile organic compounds from biogenic emissions: Measured yields and atmospheric implications. Proc. Nat1. Acad. Sci. U. S. A. 2015, 112, (23), 7123-7128.

3. Tröstl, J.; Chuang, W. K.; Gordon, H.; Heinritzi, M.; Yan, C.; Molteni, U.; Ahlm, L.; Frege, C.; Bianchi, F.; Wagner, R., The role of low-volatility organic compounds in initial particle growth in the atmosphere. Nature 2016, 533, (7604), 527.

4. Shrivastava, M.; Cappa, C. D.; Fan, J.; Goldstein, A. H.; Guenther, A. B.; Jimenez, J. L.; Kuang, C.; Laskin, A.; Martin, S. T.; Ng, N. L., Recent advances in understanding secondary organic aerosol: Implications for global climate forcing. Rev. Geophys. 2017, 55, (2), 509-559. 5. Spracklen, D.; Jimenez, J.; Carslaw, K.; Worsnop, D.; Evans, M.; Mann, G.; Zhang, Q.; Canagaratna, M.; Allan, J.; Coe, H., Aerosol mass spectrometer constraint on the global secondary organic aerosol budget. Atmos. Chem. Phys. 2011, 11, (23), 12109-12136.

6. Gong, Y.; Chen, Z.; Li, H., The oxidation regime and SOA composition in limonene ozonolysis: roles of different double bonds, radicals, and water. Atmos. Chem. Phys. 2018, 18, (20), 1510515123.

7. Enami, S.; Colussi, A. J., Criegee Chemistry on Aqueous Organic Surfaces. J. Phys. Chem. Lett. 2017, 8, 1615-1623.

8. Enami, S.; Colussi, A. J., Efficient scavenging of Criegee intermediates on water by surfaceactive cis-pinonic acid. Phys. Chem. Chem. Phys. 2017, 19, 17044-17051.

9. Enami, S.; Colussi, A. J., Reactions of Criegee Intermediates with Alcohols at Air-Aqueous Interfaces. J. Phys. Chem. A 2017, 121, 5175-5182. 10. Enami, S.; Hoffmann, M. R.; Colussi, A. J., Criegee Intermediates React with Levoglucosan on Water. J. Phys. Chem. Lett. 2017, 8, (16), 3888-3894. Wennberg, P. O., Atmospheric autoxidation is increasingly important in urban and suburban North America. Proc. Natl. Acad. Sci. U. S. A. 2018, 115, (1), 64-69. Radicals. J. Phys. Chem. A 2019, 123, (2), 590-600. 
J. D.; Wennberg, P. O.; Mentel, T. F., Highly Oxygenated Organic Molecules (HOM) from GasPhase Autoxidation Involving Peroxy Radicals: A Key Contributor to Atmospheric Aerosol. Chem. Rev. 2019, 119, (6), 3472-3509.

14. Claflin, M. S.; Krechmer, J. E.; Hu, W.; Jimenez, J. L.; Ziemann, P. J., Functional group composition of secondary organic aerosol formed from ozonolysis of a-pinene under high VOC and autoxidation conditions. ACS Earth Space Chem. 2018, 2, (11), 1196-1210.

15. Zhang, X.; Lambe, A. T.; Upshur, M. A.; Brooks, W. A.; Gray Bé, A.; Thomson, R. J.; Geiger, F. M.; Surratt, J. D.; Zhang, Z.; Gold, A., Highly oxygenated multifunctional compounds in a-pinene secondary organic aerosol. Environ. Sci. Technol. 2017, 51, (11), 5932-5940.

16. Hiatt, R.; Mill, T.; Mayo, F. R., Homolytic decompositions of hydroperoxides .i. Summary and implications for autoxidation. J. Org. Chem. 1968, 33, (4), 1416-\&.

17. Kharasch, M.; Fono, A.; Nudenberg, W., The chemistry of hydroperoxides. III. The free-radical decomposition of hydroperoxides. J. Org. Chem. 1950, 15, (4), 763-774.

18. Sanchez, J.; Myers, T. N., Peroxides and peroxide compounds, organic peroxides. Kirk $\begin{array}{llll}\text { Othmer encyclopedia of chemical } & \text { 2000, }\end{array}$ https://doi.org/10.1002/0471238961.1518070119011403.a01L.

19. Tong, H.; Zhang, Y.; Filippi, A.; Wang, T.; Li, C.; Liu, F.; Leppla, D.; Kourtchev, I.; Wang, K.; Keskinen, H.-M., Radical Formation by Fine Particulate Matter Associated with Highly Oxygenated Molecules. Environ. Sci. Technol. 2019.

20. Tong, H. J.; Arangio, A. M.; Lakey, P. S. J.; Berkemeier, T.; Liu, F. B.; Kampf, C. J.; Brune, W. H.; Poschl, U.; Shiraiwa, M., Hydroxyl radicals from secondary organic aerosol decomposition in water. Atmos. Chem. Phys. 2016, 16, (3), 1761-1771.

21. Mertes, P.; Pfaffenberger, L.; Dommen, J.; Kalberer, M.; Baltensperger, U., Development of a sensitive long path absorption photometer to quantify peroxides in aerosol particles (PeroxideLOPAP). Atmos. Meas. Tech. 2012, 5, (10), 2339-2348.

22. Krapf, M.; El Haddad, I.; Bruns, E. A.; Molteni, U.; Daellenbach, K. R.; Prévôt, A. S.; Baltensperger, U.; Dommen, J., Labile peroxides in secondary organic aerosol. Chem 2016, 1, (4), 603-616.

23. Fuller, S.; Wragg, F.; Nutter, J.; Kalberer, M., Comparison of on-line and off-line methods to quantify reactive oxygen species (ROS) in atmospheric aerosols. Atmos. Environ. 2014, 92, 97-103. 24. Qiu, J.; Ishizuka, S.; Tonokura, K.; Enami, S., Interfacial vs Bulk Ozonolysis of Nerolidol. Environ. Sci. Technol. 2019, 53, 5750-5757.

25. Qiu, J.; Ishizuka, S.; Tonokura, K.; Colussi, A. J.; Enami, S., Water Dramatically Accelerates the Decomposition of alpha-Hydroxyalkyl-Hydroperoxides in Aerosol Particles. J. Phys. Chem. Lett. 2019, 10, 5748-5755.

26. Guenther, A. B.; Jiang, X.; Heald, C. L.; Sakulyanontvittaya, T.; Duhl, T.; Emmons, L. K.; Wang, X., The Model of Emissions of Gases and Aerosols from Nature version 2.1 (MEGAN2.1): an extended and updated framework for modeling biogenic emissions. Geosci. Model Dev. 2012, 5, (6), 
1471-1492.

521

522

523

524

525

526

527

528

529

530

531

532

533

534

535

536

537

538

539

540

541

542

543

544

545

546

547

548

549

550

551

552

553

554

555

556

557

27. Hiatt, R. R.; Mill, T.; Irwin, K. C.; Castleman, J. K., Homolytic decompositions of hydroperoxides. II. Radical-induced decompositions of tert-butyl hydroperoxide. J. Org. Chem. 1968, 33, (4), 1421-1428.

28. Zhao, R.; Lee, A.; Soong, R.; Simpson, A.; Abbatt, J., Formation of aqueous-phase $\alpha^{-}$ hydroxyhydroperoxides (a-HHP): potential atmospheric impacts. Atmos. Chem. Phys. 2013, 13, (12), 5857-5872.

29. Chevallier, E.; Jolibois, R. D.; Meunier, N.; Carlier, P.; Monod, A., "Fenton-like" reactions of methylhydroperoxide and ethylhydroperoxide with $\mathrm{Fe} 2+$ in liquid aerosols under tropospheric conditions. Atmos. Environ. 2004, 38, (6), 921-933.

30. Deguillaume, L.; Leriche, M.; Chaumerliac, N., Impact of radical versus non-radical pathway in the Fenton chemistry on the iron redox cycle in clouds. Chemosphere 2005, 60, (5), 718-724.

31. Leffler, J.; More, A., Decomposition of bicyclo [2.2. 2]-1-formyl and pivaloyl peroxides. Journal of the American Chemical Society 1972, 94, (7), 2483-2487.

32. Li, J.; Perdue, E. M.; Pavlostathis, S. G.; Araujo, R., Physicochemical properties of selected monoterpenes. Environ. Intern. 1998, 24, (3), 353-358.

33. Zhang, X.; McVay, R. C.; Huang, D. D.; Dalleska, N. F.; Aumont, B.; Flagan, R. C.; Seinfeld, J. H., Formation and evolution of molecular products in $\alpha$-pinene secondary organic aerosol. Proc. Nat1. Acad. Sci. U. S. A. 2015, 112, (46), 14168-14173.

34. Ferre-Aracil, J.; Cardona, S. C.; Navarro-Laboulais, J., Determination and Validation of Henry's Constant for Ozone in Phosphate Buffers Using Different Analytical Methodologies. Ozone Sci. Engine. 2015, 37, (2), 106-118.

35. Ershov, B. G.; Panich, N. M., Spectrophotometric determination of ozone in solutions: Molar absorption coefficient in the visible region. Spectrochim. Acta A 2019, 217, 39-43.

36. Hoigne, J.; Bader, H.; Haag, W. R.; Staehelin, J., Rate constants of reactions of ozone with organic and inorganic-compounds in water. III. inorganic-compounds and radicals. Water Res. 1985, 19, (8), 993-1004.

37. Enami, S.; Vecitis, C. D.; Cheng, J.; Hoffmann, M. R.; Colussi, A. J., Global inorganic source of atmospheric bromine. J. Phys. Chem. A 2007, 111, (36), 8749-8752.

38. Zhou, S. M.; Rivera-Rios, J. C.; Keutsch, F. N.; Abbatt, J. P. D., Identification of organic hydroperoxides and peroxy acids using atmospheric pressure chemical ionization-tandem mass spectrometry (APCI-MS/MS): application to secondary organic aerosol. Atmos. Meas. Tech. 2018, 11, (5), 3081-3089.

39. Zhao, R.; Kenseth, C. M.; Huang, Y.; Dalleska, N. F.; Seinfeld, J. H., Iodometry-Assisted Liquid Chromatography Electrospray Ionization Mass Spectrometry for Analysis of Organic Peroxides: An Application to Atmospheric Secondary Organic Aerosol. Environ. Sci. Technol. 2018, 52, (4), 2108-2117.

40. Zhao, R.; Kenseth, C. M.; Huang, Y.; Dalleska, N. F.; Kuang, X. M.; Chen, J.; Paulson, S. E.; 
558

559

560

561

562

563

564

565

566

567

568

569

570

571

572

573

574

575

576

577

578

579

580

581

582

583

584

585

586

587

588

589

590

591

592

593

594

595

Seinfeld, J. H., Rapid Aqueous-Phase Hydrolysis of Ester Hydroperoxides Arising from Criegee Intermediates and Organic Acids. J. Phys. Chem. A 2018, 122, 5190-5201.
41. Allen, H. M.; Crounse, J. D.; Bates, K. H.; Teng, A. P.; Krawiec-Thayer, M. P.; Rivera-Rios, J.

C.; Keutsch, F. N.; St. Clair, J. M.; Hanisco, T. F.; Møller, K. H.; Kjaergaard, H. G.; Wennberg, P.

O., Kinetics and Product Yields of the $\mathrm{OH}$ Initiated Oxidation of Hydroxymethyl Hydroperoxide. J. Phys. Chem. A 2018, 122, (30), 6292-6302.

42. Zhou, S.; Joudan, S.; Forbes, M. W.; Zhou, Z.; Abbatt, J. P. D., Reaction of Condensed-Phase Criegee Intermediates with Carboxylic Acids and Perfluoroalkyl Carboxylic Acids. Environ. Sci. Technol. Lett. 2019, 6, 243-250.

43. Qiu, J.; Ishizuka, S.; Tonokura, K.; Enami, S., Reactions of Criegee Intermediates with Benzoic Acid at the Gas/Liquid Interface. J. Phys. Chem. A 2018, 122, 6303-6310.

44. Qiu, J.; Ishizuka, S.; Tonokura, K.; Colussi, A. J.; Enami, S., Reactivity of Monoterpene Criegee Intermediates at Gas-Liquid Interfaces. J. Phys. Chem. A 2018, 122, (39), 7910-7917.

45. Finlayson-Pitts, B. J.; Pitts, J. N., Chemistry of the upper and lower atmosphere. Academic Press: San Diego, CA, 2000.

46. Winterhalter, R.; Herrmann, F.; Kanawati, B.; Nguyen, T. L.; Peeters, J.; Vereecken, L.; Moortgat, G. K., The gas-phase ozonolysis of beta-caryophyllene (C15H24). Part I: an experimental study. Phys. Chem. Chem. Phys. 2009, 11, (21), 4152-4172.

47. Criegee, R., Mechanism of ozonolysis. Angew. Chem. Int. Edt. 1975, 14, 745-752.

48. Witkowski, B.; Gierczak, T., Early stage composition of SOA produced by alpha-pinene/ozone reaction: alpha-Acyloxyhydroperoxy aldehydes and acidic dimers. Atmos. Environ. 2014, 95, 59-70. 49. Neta, P.; Huie, R. E., Rate constants for reactions of nitrogen oxide (NO3) radicals in aqueous solutions. J. Phys. Chem. 1986, 90, (19), 4644-4648.

50. Lakey, P. S.; Berkemeier, T.; Tong, H.; Arangio, A. M.; Lucas, K.; Pöschl, U.; Shiraiwa, M., Chemical exposure-response relationship between air pollutants and reactive oxygen species in the human respiratory tract. Sci. Rep. 2016, 6, 32916.

51. Rissanen, M. P.; Kurtén, T.; Sipilä, M.; Thornton, J. A.; Kausiala, O.; Garmash, O.; Kjaergaard, H. G.; Petäjä, T.; Worsnop, D. R.; Ehn, M.; Kulmala, M., Effects of Chemical Complexity on the Autoxidation Mechanisms of Endocyclic Alkene Ozonolysis Products: From Methylcyclohexenes toward Understanding a-Pinene. J. Phys. Chem. A 2015, 119, (19), 4633-4650.

52. Anslyn, E. V.; Dougherty, D., Modern Physical Organic Chemistry. University Science Books: 2005.

53. Qiu, J.; Ishizuka, S.; Tonokura, K.; Sato, K.; Inomata, S.; Enami, S., Effects of pH on Interfacial Ozonolysis of a-Terpineol. J. Phys. Chem. A 2019, 123, 7148-7155.

54. Zhou, X.; Lee, Y. N., Aqueous solubility and reaction kinetics of hydroxymethyl hydroperoxide. J. Phys. Chem. 1992, 96, (1), 265-272.

55. O'Brien, R. E.; Kroll, J. H., Photolytic Aging of Secondary Organic Aerosol: Evidence for a Substantial Photo-Recalcitrant Fraction. J. Phys. Chem. Lett. 2019, 10, 4003-4009. 
596

597

598

599

600

601

602

603

604

605

606

607

608

609

610

611

612

613

614

615

616

617

618

619

620

621

622

623

624

625

626

627

628

629

630

631

632

633

56. Enami, S.; Ishizuka, S.; Colussi, A. J., Chemical signatures of surface microheterogeneity on liquid mixtures. J. Chem. Phys. 2019, 150, (2), 024702.

57. Kononov, L. O., Chemical reactivity and solution structure: on the way to a paradigm shift? RSC Adv. 2015, 5, (58), 46718-46734.

58. Rak, D.; Sedlák, M., On the Mesoscale Solubility in Liquid Solutions and Mixtures. J. Phys. Chem. B 2019, 123, (6), 1365-1374.

59. Subramanian, D.; Boughter, C. T.; Klauda, J. B.; Hammouda, B.; Anisimov, M. A., Mesoscale inhomogeneities in aqueous solutions of small amphiphilic molecules. Faraday Discuss. 2013, 167, (0), 217-238.

60. Yinnon, C. A.; Yinnon, T. A., Domains in aqueous solutions: theory and experimental evidence. Modern Phys. Lett. B 2009, 23, (16), 1959-1973.

61. Nagasaka, M.; Yuzawa, H.; Kosugi, N., Microheterogeneity in Aqueous Acetonitrile Solution Probed by Soft X-ray Absorption Spectroscopy. J. Phys. Chem. B 2020, 124, (7), 1259-1265.

62. Mukherjee, D.; Ortiz Rodriguez, L. I.; Hilaire, M. R.; Troxler, T.; Gai, F., 7-Cyanoindole fluorescence as a local hydration reporter: application to probe the microheterogeneity of nine water-organic binary mixtures. Phys. Chem. Chem. Phys. 2018, 20, (4), 2527-2535.

63. Krieger, U. K.; Marcolli, C.; Reid, J. P., Exploring the complexity of aerosol particle properties and processes using single particle techniques. Chem. Soc. Rev. 2012, 41, (19), 6631-6662.

64. Marsh, A.; Rovelli, G.; Song, Y.-C.; Pereira, K. L.; Willoughby, R. E.; Bzdek, B. R.; Hamilton, J.; Orr-Ewing, A.; Topping, D. O.; Reid, J. P., Accurate Representations of the Physicochemical Properties of Atmospheric Aerosols: When are Laboratory Measurements of Value? Faraday

\section{Discuss. 2017, DOI: 10.1039/C7FD00008A}

65. Reid, J. P.; Dennis-Smither, B. J.; Kwamena, N.-O. A.; Miles, R. E.; Hanford, K. L.; Homer, C. J., The morphology of aerosol particles consisting of hydrophobic and hydrophilic phases: hydrocarbons, alcohols and fatty acids as the hydrophobic component. Phys. Chem. Chem. Phys. 2011, 13, (34), 15559-15572.

66. Fang, T.; Guo, H.; Zeng, L.; Verma, V.; Nenes, A.; Weber, R. J., Highly Acidic Ambient Particles, Soluble Metals, and Oxidative Potential: A Link between Sulfate and Aerosol Toxicity. Environ. Sci. Technol. 2017, 51, (5), 2611-2620.

67. Guo, H.; Sullivan, A. P.; Campuzano-Jost, P.; Schroder, J. C.; Lopez-Hilfiker, F. D.; Dibb, J. E.; Jimenez, J. L.; Thornton, J. A.; Brown, S. S.; Nenes, A.; Weber, R. J., Fine particle pH and the partitioning of nitric acid during winter in the northeastern United States. J. Geophys. Res. Atmos. 2016, 121, (17), 10355-10376.

68. Bougiatioti, A.; Nikolaou, P.; Stavroulas, I.; Kouvarakis, G.; Weber, R.; Nenes, A.; Kanakidou, M.; Mihalopoulos, N., Particle water and $\mathrm{pH}$ in the eastern Mediterranean: source variability and implications for nutrient availability. Atmos. Chem. Phys. 2016, 16, (7), 4579-4591.

69. Witkowski, B.; Gierczak, T., Early stage composition of SOA produced by a-pinene/ozone reaction: a-Acyloxyhydroperoxy aldehydes and acidic dimers. Atmos. Environ. 2014, 95, 59-70. 
634 70. Shiraiwa, M.; Selzle, K.; Poschl, U., Hazardous components and health effects of atmospheric 635 aerosol particles: reactive oxygen species, soot, polycyclic aromatic compounds and allergenic 636 proteins. Free Radical Res. 2012, 46, (8), 927-939.

637 71. Shiraiwa, M.; Ueda, K.; Pozzer, A.; Lammel, G.; Kampf, C. J.; Fushimi, A.; Enami, S.; Arangio, 638 A. M.; Fröhlich-Nowoisky, J.; Fujitani, Y., Aerosol health effects from molecular to global scales. 639 Environ. Sci. Technol. 2017, 51, (23), 13545-13567.

640 72. Calvert, J. G.; Pitts, J. N., Photochemistry. Wiley: New York, 1966.

641 


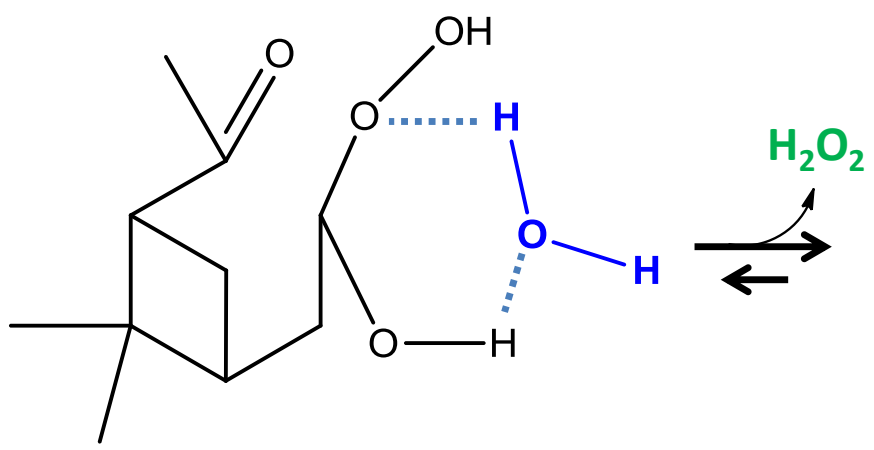

$\alpha$-Hydroxyalkyl-hydroperoxide

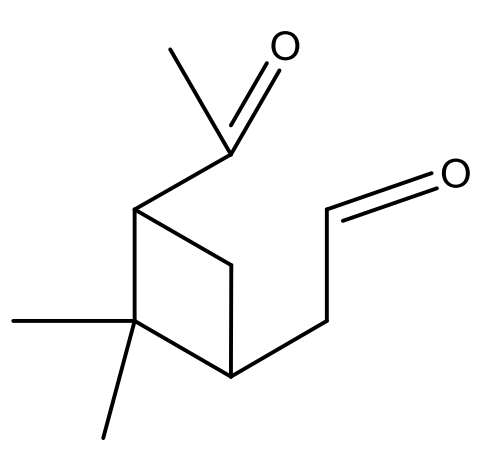

Functionalized aldehyde

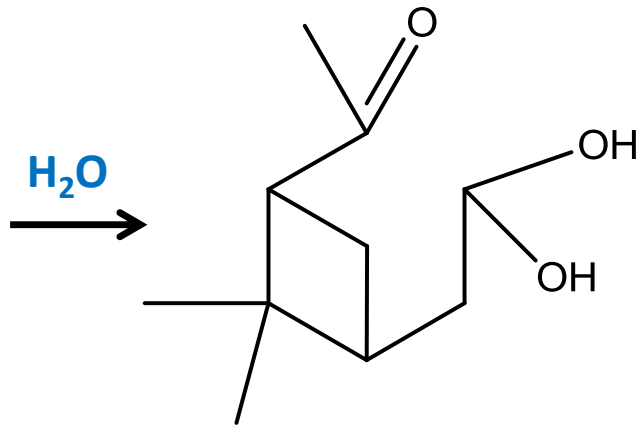

Functionalized gem-diol

$\mathrm{ROOH} \theta \mathrm{RO} \cdot+\cdot \mathrm{OH}$ 